\title{
Communicating Influence Versus Asserting Dominance - Positions of Agreeable and Disagreeable People in Social Groups
}

\author{
Ramil Karimov ${ }^{1, *}$ \\ ${ }^{1}$ Department of Social Philosophy, Peoples' Friendship University of Russia (RUDN University), Moscow, \\ Russia \\ *Corresponding author. Email: Karimovramil@gmail.com
}

\begin{abstract}
The following article deals with the aspects of group communication, distinguishing between social dominance and social influence. While communicative markers of dominance are quite prominent, and may even be observed through physical features and obvious behavioral markers, the markers of influence are not quite as obvious. Using graph theory, social network theory, and social impact theory, as well as the latest research in the field of biology and behavior, the author derives some markers of social influence, also linking the behavioral and communicational preferences of dominant or influential individuals to their personality traits.
\end{abstract}

Keywords: communication, connectivity, social group communication, social influence, social

dominance, agreeableness, disagreeableness, consensus task, speed of reach, sources of influence

\section{INTRODUCTION}

While power in social groups is mostly displayed as dominance and often strongly associated only with this, it's important to note that dominance is only one trait that may define power level of an individual in a group. There is an actual and important distinction between social dominance and social influence.

Among animals, social dominance is mostly associated with a higher level of access to resources, privileges when dividing those resources obtained by the group, more frequent mating opportunities, as well as privilege in choosing more suitable mates, and increased survival ratio due to being able to avoid certain risks related to predation. However, dominance obviously comes with an increased risk of being challenged or betrayed by one's own social peers, higher level of stress hormones in the bloodstream, also lasting for longer periods of time, which increases the risk of various deceases, as well as keeping up higher metabolic rate. All of those things are not uncommon among humans as well [1]. So, it's safe to say that dominance is mostly about access of a unit to resources and means of procreation.

Social influence, on the other hand, is often associated with the ability of a unit to affect its social peers in a certain (or even desired) way, or the ability of a social group to correct behavior of a unit/individual. While social dominance may be observed quite easily by certain physical and behavioral attributes of an individual, as well as by its position in social hierarchy of a group, social influence is much harder to measure. One particular reason is that an influential individual is much harder to spot, not having obvious visual markers; the other major reason is that whereas there are only very few dominant individuals, there might be much more of influential individuals having their specific areas of influence. And the third important reason is that the dominance hierarchy is quite stable and rigid, whereas the influence hierarchy might be more erratic and agile.

So, here is a burning question - how dominance and influence correlate? Does dominance lead to influence, or does influence lead to dominance, or are they unrelated social phenomena? Are they two sides of the same thing that constitutes power, or do they exist in opposition to one another? And what types of individuals may be dominant and what types of individuals may be influential? But, before jumping into the questions of connection between dominance and influence, as well as the question of what type of individual is most likely to be dominating and what type is most likely to be influential in a social group, and whether it might 
be the same individual, there is a need to look into a few theories proposing markers of social influence.

\section{MARKERS OF INFLUENCE AND DOMINANCE IN GRAPH THEORY AND SOCIAL NETWORK THEORY}

Using graph theory and social network theory, the influence may be defined firstly by the number of nodes connected to the unit. Graph theory is used in describing social groups as a series of nodes (or points) connected by edges (or lines) [2]. Social network theory describes the dynamic and patterns in those graphs [3] [4]. So, according to those theories, the connectivity level of a node matters a lot. The more connected is a node to the other nodes, the more central this point becomes in a given group. So, the center of group is there, where the most connected individual is.

Secondly, the influence in a graph model may be described by the number of steps one should make in order to reach the necessary node. In other words - the level of influence is also determined by the speed of which a node is reachable. The less there is a number of nodes one have to pass in order to reach the desired unit, the faster the influence of this unit spreads. Of course, reaching the unit in a group may not be only physical, and is often not physical at all, but leaves in the realm of communication - reach of information.

Thirdly, in graph model the vector of a node determines a great deal. In a graph model, the objects may move differently, having different capacities and power levels that determine the agility of movement [5]. So, the most influential node should not only be the most connected, and relatively fast to reach, but this individual should reach others at its will, not the other way around. It would want to have more vectors to be targeted in outwards direction, rather than the inwards direction. If a unit is only highly connected and fast to reach, it may indicate high level of its influence in a group, but if this node doesn't move at all, the vectors are always closing in on it, and not the other way around, then it's safe to say that this node is the most used by others and not the most influential. Of course, when people use something or someone, they depend on it, and it constitutes some level of its power, sometimes even a great level of power especially if we define power as relations of dependence. But, the unit has more power or influence, when it "plays its own game" so to speak, and is not only passively used by others. In this third point possibly lies the distinction between dominance and influence - on the one hand, imposing one's point of view or mode of operating is a marker of dominance, on the other hand, being connected is a market of influence. So, that is where those two things meet - an influential person might be the dominant one, if also imposes its modus operandi and viewpoints onto the nodes that are connected to it, and it's the most connected node. Is it possible to have one person uniting influence and dominance within itself? And, more importantly, would it necessarily lead to the overall success of the group, if the influence meets dominance in one person? But let's not get ahead of ourselves.

The fourth marker of influence is a qualitative one, and may not be described by social network or graph theory - the level of depth of such interactions, the level of penetration of the influence that this given unit possesses over other units/nodes. This marker is quite wide in its nature and may be described by so many theories primitive group theory, Rawlins William's friendship theory, Abraham Maslow hierarchy of needs, and basically all of psychology and many more [6] [7]. This marker may only be measured using qualitative methods and may be observed only post-factum, whether the influence was great and deep or was insignificant. Today, in the era of the social media influence, we measure influence of an opinion leader using first two criteria, which are quantitative ones and easy to measure. However, it takes us back 50-70 years in studying of communications, as in works of G. Lasswell, P. Lazarsfeld, M. McCombs and D. Shaw and others, and the level of depth of influence is still quite hard to measure - one bulletproof way is to judge it by the end result of a media campaign or electoral campaign - people either by your product or choose your candidate or they don't. Even then, there are few other markers to consider.

\section{SIMILARITIES BETWEEN MARKERS IN GRAPH/SOCIAL NETWORK THEORY AND SOCIAL IMPACT THEORY}

Social impact theory proposed somewhat similar markers of influence [7]. First of all, it's strength of the influencer, which is not a physical strength, although that might be one component of it. However, in social impact theory strength is the indicator of social proof of the influencer in the eyes of the influenced. So, here the influence and dominance meet, for sure. The dominant unit, especially if it's male, often possesses the necessary physical attributes, like physical power and higher aggression level, so as a result of that, but not exclusively that, it is often has a lot of social proof. So, this marker is similar to the third marker we named within the graph/social network theories. Secondly, it's immediacy, which refers to
special and temporal proximity of
something/someone that influences to
something/someone that is being influenced. So, this marker corresponds to the second marker of 
graph/social network theories, such as the speed of reach.

And last, but not least - number of sources of influence. This marker corresponds to the level of connectivity in graph/social network theories, but evidently highlights some different aspect of that. Given that social impact theory deals more with how the system or a group affects a unit, rather than how the unit affects the system, it considers that the more units are acting unanimously, the more success in shaping the whole system they would have, so it's safe to say, that the more influence they have. From this, it may be concluded that the influence is something that might grow when shared with others, whereas dominance is something that only few can possess and is something that dissolves, ones shared. As a simple example, among fish or primates, the larger the group is spread in the wild, the more sources of income of resources they have, the less control dominant males, as well as females exude over the behavior of subordinate males and females, thus subordinates have more opportunities to procreate, act a little bit more independently, organize little substructures within the group[9] [10].

So, sharing the power, when talking about dominance, is diminishing the power. As opposed to sharing influence is increasing influence. So, yet again, it is quite similar to communication and spreading of information. The more sources of the same message are there, the more influential the message becomes. As we may observe, the influence may be somehow related to sharing of information. This point is actually quite greatly demonstrated in a very recent study named "Behavioral traits that define social dominance are the same that reduce social influence in a consensus task" by a group of researchers - Mariana Rodriguez-Santiago, Paul Nührenberg, James Derry, Oliver Deussen, Fritz A. Francisco, Linda K. Garrison, Sylvia F. Garza, Hans A. Hofmann, Alex Jordan [11]. So, here' the short of it.

\section{THE EFFICIENCY OF SOCIAL DOMINANCE MODEL VS SOCIAL INFLUENCE MODEL IN A CONSENSUS TASK}

The researchers examined the behavior of cichlid fish Astatotilapia burtoni in controlled conditions. Firstly, they've established a baseline for A.burtoni behavior by placing them in an aquarium and examining their behavioral patterns. The results of the experiment showed that, to quote "phenotypically dominant males are more central in social networks and have a strong influence on group movement" [12]. According to the results, the dominant males are much more frequently initiate the movement by starting to move themselves. So in routine conditions with no specific goals, dominance somewhat equals influence. The authors of the experiment state that the dominant individual chases subordinates, thus generating fear. The subordinates follow the leader. However, the study shows that "...dominant males were more spatially distant from other group members than were subordinate males...". "However, there was no difference in the visual connectivity to other group members between dominants and subordinates..." [13]. It's important to note that central position in a group is occupied by alphas, which is not uncommon, not only among fish, but primates or insects as well [14] [15]. Dominant males occupy central positions in a group. They have the authority, they have social proof. However, they are the furthest from others, even though they keep up the eye contact, observing the group, thus, putting it in terms of social network theory - they have a diminished speed of reach. So, when the new information comes into the group, the leader may not know it first, but learns it eventually. Examples of this we may see every day - more often than not the boss is the last to know the gossip, circulating among the employees in the office; the teacher may not know the half of what its students are discussing. Because they have stronger bonds and dominant individual disrupts those bonds by simply being in the room.

However, the most interesting part of the study, allowing to more clearly separate influence from dominance, is the next one. The designers of the experiment "...trained dominant and subordinate males on an association task and then placed these informed males into groups of individuals naïve to that task" [16]. And then they measured the speed with which the group reaches consensus on the task. Simply put, there is one tank with naïve subordinates, where an informed dominant male was put in. And there is a tank with naïve subordinates and a naïve dominant male, where an informed subordinate was added. And there is a tank with only naïve fish. "...groups containing dominant male informants did not reach consensus faster than naïve groups...". "...groups containing a subordinate male informant achieved consensus significantly faster than both naïve and dominant male informant groups..." [17].

So does it mean that dominant leaders are bad influencers? In this regard, it's seems that there is another point to add, the one that is hard to measure within the framework of the experiments on fish. It's the disruption of social hierarchy when placing an informed dominant male into the group of naïve subordinates. The new dominant individual might need to assert his dominance first, which is why it might lose time in a consensus task, while a new informed subordinate male doesn't disrupt an established social hierarchy within the group. In first tank, the dominant male is the source of 
information and also represents change in social hierarchy. In second one, the subordinate male is only the source of information and not social change. So, it might be that the dominant males still act as an efficient leader in more complex tasks. The only difference is the established social structures.

If we try to project those results on people's group dynamics, then the dominant male is also the one with new information and a newcomer in the given social group, he may have a hard time to generate consensus, he doesn't generate a lot of trust, thus subordinates are reluctant to do his bidding, and are afraid of him. So, on the side note, fear is not the best incentive in complex group tasks. With humans it's possible to give information to people without placing them in different aquariums for a few days, meaning without breaking social group structures. Then it would be interesting to see if the end result is the same. However, whereas with humans it's possible to pass one obstacle, there are even more others to consider. For instance, in humans it may also have a lot to do with trust, but it remains to be determined whether the dominant or subordinate males are more trustworthy. It may also have a lot to do with the nature of the task, and whether benefits of it outweigh its risks, which in its turn has a lot to do with the individual benefits that each member of the group receives upon completing the tasks, as well as compared to the amount of benefits that a dominant individual receives, as well as the group as a whole. It also has a lot to do with the very nature of social connections that a group has, and strength of those social bonds, not to mention simple things like the size of the group, and many others.

Of course, the universality of this is yet to be determined. Those behavioral and hierarchical dynamics may vary from species to species and possibly other parameters. Such as a level of intellect, or various animals have various modes of operating within a group. Some are more social, some are quite the loaners, which may be a crucial factor. Also, there are a lot of animals with a fightbased mode of leadership positions, where the strongest rules the group, and there are a lot of animals with the inheritance-model of dominance, where dominance is not won in a fight, but passed on to the next worthy individual.

Anyway, the experiment shows the edge that a simple piece of information may provide in right circumstances, and how a subordinate unit possessing information may become the most influential in a group in a situation when a common goal is to be achieved. So influence and efficiency are might be somewhat correlated. While the dominant male, even possessing needed information, may become the very thing that interferes with the achievement of the goal and shows overall lover efficiency.

\section{AGREEABLENESS VS DISAGREEABLENESS AND RELATION TO DOMINANCE AND INFLUENCE}

So, if the dominance is mostly about the resources, the influence lives in the realm of information and ways of communicating and connecting to others. Not surprisingly, the influence is more about possessing and transmitting information, it's a power of knowledge and communication, whereas the dominance is a power of brutal force, position in the hierarchy.

This also somewhat explains the traditional differences between power specificities among males versus females, at least among humans. Men try to occupy positions of power by climbing up to the top of the dominance hierarchy, which is often done by brutal force and all other, more civilized, derivatives of the brutal force. Women, however, use more often than not, methods of affecting reputation of members of the group. While, males much more often resort to violence and we might even say, are permitted to resort to violence, for women it's not the case. So, throughout history women were known to use other social leavers, affecting reputation of other people, such as gossip, rumors and innuendos, as well as Dr. Ditta M. Oliker put it, excluding, ignoring, teasing, and hostile body language [18]. However, it doesn't mean that men don't use those tools at all.

Reputation in a society is a powerful thing in itself. Some Polynesian and Oceania tribes consider being shamed by the tribe or exile worse than death, because while a dead individual is still considered part of the tribe by occupying a place in it, and his family will be taken care of; the dishonored or exiled individual loses its place in the tribe, and its family loses protection and privileges. So, traditionally speaking (in ancient harems for example), women fought for dominance and climbed up the hierarchy ladder by using influence levers, while men used dominance leavers. So men are prone to use force and violence - markers of dominance. Women are prone to use information, gossip, rumors - markers of influence. This point becomes especially important in the context of modernity, where new ways of communicating and forming social proof and reputation, as well as destroying social proof and reputation emerge [19] [20]. For instance, as A. Linde puts it, new forms of social proof control, that emerged quite recently, led by the government and aided by the internetbased social networks and technology "leads only to the programming of consciousness of the citizens...", as well as to the "...emasculation of the human personality itself..." [21] 
In addition, there are many forms of symbolic violence, which differ from the real violence, but being somewhat similar to it at the same time [22]. Whether symbolic violence is a form of dominance, as the real violence is, or could rather be characterized as a form of influence is a topic for another time, but an interesting one none the less.

While gender specificities are one way to explain those different approaches to power, there is another, more promising way - Five factor model or better known as Big Five theory [23] [24]. Big five personality traits theory describes five major personality traits that define human behavior. Those traits are varying within them in a scale from one extremity to another, while personality is always formed from a mix of those variations.

First factor is openness, which defines the level of curiosity of a person and the readiness to have new experiences, and to innovate. It varies from curious, inventive and innovative person at one end to a cautions, conservative and consistent person at another end. Second factor is extraversion, which goes from outgoing personality to reserved personality. Third factor is conscientiousness, which means that the person either highly reflective, self-controlling and organized or either careless, and not highly reflective. The fourth factor is neuroticism, which defines the level of confidence and overall nervousness - varying from a very sensitive and fragile person to a very resilient one. And the firth factor, which is one that present most interest within the framework of this article agreeableness. Agreeableness and disagreeableness are two extremes between compassionate person and callous one. Agreeableness is often mixed with the term "emotional intellect". From one hand, agreeable person may be called a soft one, a friendly one and an easy to get along with. On the other hand, highly agreeable people may often be associated with doormats, person unable to take a stand, or to be confrontational. Disagreeable people, on the other hand, thrive on conflict. They may be called as hard to deal with, unpleasant and unfriendly, as well as dominating.

This theory might better explain (rather than the gender-based differences) the distinction between a person resorting to the tools of dominance, such as violence, or the tools of influence - such as manipulating information. The disagreeable person, especially if it also is low in neuroticism is most likely to be a dominating one. The agreeable person, especially if it also is high in conscientiousness would be most likely to use the influence methods. This also explains the difference between males' and females' preferences in choosing tools of achieving power, given that, generally speaking, women are more agreeable than men. So, the Big Five theory also explains why there are some women who resort to violence and seek dominance, and why there are some men who seek influence and use gossip, rumors, ignoring and teasing. It might simply depend on the mix of personality traits in a person regardless of gender, however, there are certain correlations between gender and how big five are manifested - women tend to be, generally speaking, more agreeable and more conscientiousness, than men, however it's not written in stone.

\section{CONCLUSION}

So, to conclude all that has been said. Dominance and influence, while interconnected, have different social markers. Dominance is more about access to resources and means of procreation, while guarding this access, controlling its distribution and chasing away competitors. Influence is more about communication and transmitting of information, as well as the level of connectivity, speed of access and the increasing number of its accolades. The more influential individuals the group has, the more pressure of influence each member of the group is submitted to.

If we add to this the factor of vector, in other words, if the unit more often transmits the information (which to some degree also includes the modus operandi and overall worldview within it) rather than receiving it, it also has a high level of dominance, as well as influence.

So, there might be a correlation between the influence-based mode of group dynamic control and efficiency of completing group tasks. The influence-based model might turn out to be more efficient than the dominance based one, when achieving certain group goals. Dominant individuals are less efficient when the group performance is concerned, because dominant ones disrupt social interactions in a group, thus lowering the connectivity and speed of reach of its members. So, it's better to have a separate dominant individual and an influential one. That is why the model in business when there is a boss, who is distanced from its working group and there is a deputy, who connects the group to the boss is quite efficient.

That would also explain why the phenomenon of so-called "éminence grise" (grey eminence or grey cardinals) is so prominent throughout the history, and even one could argue that historic periods known for being actually ruled mostly by those grey figures may be called as very controversial, but quite productive. This is a debatable point, for sure, but it may be supported by a few examples - Cardinal Richelieu in XVII century France; Martin Bormann in Germany during World War II; Giulio Andreotti - Prime Minister of Italy in 1950- 90s; USA Director of 
Policy Planning Dennis Ross and USA Vice President Dick Cheney between 1990 and 2010.

As to what type of personality is more probable to exude dominant and influential behavior - it would be fair to generalize that agreeable and conscientious people may display influential behavior, while disagreeable, low in neuroticism people display dominant behavior.

So, we may say that the influence may mostly be attributed to what we call communication mediators with high connectivity level - the communications units that gather high number of social interactions within them, such as deputy in the office, ambassadors in politics, headman of a pupils' group in school, contemporary opinion leaders on the internet etc.

\section{References}

[1] Huntingford F., Turner A.K. "Animal Conflict". Chapman and Hall, 1987;

[2] Biggs N., Lloyd E., Wilson R. "Graph Theory 1736-1936". Oxford University Press, 1986;

[3] Freeman L. Centrality in Social Networks: II Experimental results // Social Networks. -1979. - Vol. 2. - № 2. P.119-141;

[4] Cook K.S., Emerson R.M., Gillmore M.R., Yamagishi T. "The Distribution of Power in Exchange Networks: Theory and Experimental Results" // American Journal of Sociology. - 1983. - № 89. - P. 275 - 305;

[5] Blau P. :Exchange and Power in Social Life". Wiley, 1964;

[6] Rawlins W. "Friendship Matters: Communication, Dialectics, and the Life Course (Communication and Social Order)". Aldine de Gruyter, 1992;

[7] Maslow, A. H. "The farther reaches of human nature". The Viking Press, 1971;

[8] Latané, B. "The psychology of social impact". American Psychologist. - 1981. - № 36 (4). - P.343-356.

[9] Chase, I. D.; Tovey, C.; Murch, P. "Two's Company, Three's a Crowd: Differences in Dominance Relationships in Isolated versus Socially Embedded Pairs of Fish" - 2003 - Vol. 140, No. 10, Models and Empirical Studies of Causes and Consequences of Dominance Hierarchies. P.1193-1217;

[10] Samuels, A.; Silk, J. B.; Rodman, P. "Changes in the dominance rank and reproductive behavior of male bonnet macaques (Macaca radiate)". - 1984 - Animal Behaviour № 32 (4) - P. 994-1003.

[11] Rodriguez-Santiago M., Nührenberg P., Derry J., Deussen O., Francisco F. A., Garrison L. K. , Garza S. F., Hofmann H. A., Jordan A.. "Behavioral traits that define social dominance are the same that reduce social influence in a consensus task" - PNAS - 2020. -117 (31) - P. 1856618573;

[12] Ibid. - P. 18567;

[13] Ibid;

[14] C.Dubuc; L. Muniz; M. Heistermann; A. Engelhardt; Widdig A. "Testing the priority-of-access model in a seasonally breeding primate species" - 2011 - Behavioral Ecology and Sociobiology - 65 (8), - P.1615-1627.

[15] Burton C., Field J. "Queuing for dominance: Gerontocracy and queue-jumping in the hover wasp Liostenogaster flavolineata" - 2007. - Behavioral Ecology and Sociobiology 61(8) - P. 1253-1259;

[16] Rodriguez-Santiago M., Nührenberg P., Derry J., Deussen O., Francisco F. A., Garrison L. K. , Garza S. F., Hofmann H. A., Jordan A.. "Behavioral traits that define social dominance are the same that reduce social influence in a consensus task" - PNAS - 2020. -117 (31) - P. 18567;

[17] Ibid;

[18] Link: https://www.psychologytoday.com/us/blog/the-longreach-childhood/201109/bullying-in-the-female-world

[19] Ivleva M.L., Kurmeleva E.M., Rudanovskaya S.V. Man and Society in the Context of Modernity/ Issues of Philosophy, №4. Moscow: «Nauka» Publishing House, 2018. - P. 191-195.

[20] Latypov, I.A., "Methodology of social differentiation of informational relations as a philosophical problem", "Journal of Siberian federal university" (Humanities \& Social sciences) (Russia), Vol. 3, 2008. ISSN 1997-1370. P. 347-353

[21] Linde A. "Comparative Analysis of Cases of Technocratic Governance and Deliberative-Democratic Self-Rule in Internet Sphere". Advances in Social Science, Education and Humanities Research. International Conference Communicative Strategies of Information Society (CSIS 2018). Advances in Social Science, Education and Humanities Research. Paris, Atlantis Press, 2016, P. 350.

[22] Tagirov $\mathrm{Ph} .$, Symbolic violence and the Other in crosscultural field (some remarks on R. Girard's and J. Baudrillard's theories). Proceedings of the 2016 International Conference on Arts, Design, and Contemporary Education (ICADCE 2016). Advances in Social Science, Education and Humanities Research. Paris, Atlantis Press, 2016, P. 1268 - 1273.

[23] Goldberg L. "The structure of phenotypic personality traits". - 1993 - American Psychologist. 48 (1). - P. 26-34.

[24] Digman J. "Personality structure: Emergence of the fivefactor model". - 1990 - Annual Review of Psychology. №41. - P.417-440. 